\title{
Ionotropic glutamate receptors of amacrine cells of the mouse retina
}

\author{
OLIVIA N. DUMITRESCU, ${ }^{1}$ DARIO A. PROTTI, ${ }^{2}$ SRIPARNA MAJUMDAR, ${ }^{1}$ \\ HANNS ULRICH ZEILHOFER, ${ }^{3}$ AND HEINZ WÄSSLE ${ }^{1}$ \\ ${ }^{1}$ Department of Neuroanatomy, Max-Planck-Institute for Brain Research, Frankfurt/Main, Germany \\ ${ }^{2}$ Department of Physiology, University of Sydney, Sydney, Australia \\ ${ }^{3}$ Department of Experimental and Clinical Pharmacology and Toxicology, University of Erlangen, Erlangen, Germany \\ (Received August 19, 2005; AcCePted September 15, 2005)
}

\begin{abstract}
The mammalian retina contains approximately 30 different morphological types of amacrine cells, receiving glutamatergic input from bipolar cells. In this study, we combined electrophysiological and pharmacological techniques in order to study the glutamate receptors expressed by different types of amacrine cells. Whole-cell currents were recorded from amacrine cells in vertical slices of the mouse retina. During the recordings the cells were filled with Lucifer Yellow/Neurobiotin allowing classification as wide-field or narrow-field amacrine cells. Amacrine cell recordings were also carried out in a transgenic mouse line whose glycinergic amacrine cells express enhanced green fluorescent protein (EGFP). Agonist-induced currents were elicited by exogenous application of NMDA, AMPA, and kainate (KA) while holding cells at $-75 \mathrm{mV}$. Using a variety of specific agonists and antagonists (NBQX, AP5, cyclothiazide, GYKI 52466, GYKI 53655, SYM 2081) responses mediated by AMPA, $\mathrm{KA}$, and NMDA receptors could be dissected. All cells $(n=300)$ showed prominent responses to non-NMDA agonists. Some cells expressed AMPA receptors exclusively and some cells expressed KA receptors exclusively. In the majority of cells both receptor types could be identified. NMDA receptors were observed in about $75 \%$ of the wide-field amacrine cells and in less than half of the narrow-field amacrine cells. Our results confirm that different amacrine cell types express distinct sets of ionotropic glutamate receptors, which may be critical in conferring their unique temporal responses to this diverse neuronal class.
\end{abstract}

Keywords: Mouse retina, Amacrine cells, Ionotropic glutamate receptors

\section{Introduction}

There are as many as 30 different types of amacrine cells in the mammalian retina (Vaney, 1991; MacNeil \& Masland, 1998). About half of them are GABAergic while the other half are glycinergic neurons. GABAergic amacrine cells are usually widefield cells and they often release other neuroactive substances in addition to GABA. Glycinergic amacrine cells are mostly smallfield cells with diffuse and sometimes bistratified dendritic trees (Pourcho \& Goebel 1985; Menger et al., 1998).

Amacrine cells receive synaptic input from bipolar cells and from other amacrine cells. The bipolar cell synapse contains a presynaptic ribbon opposed to two postsynaptic elements and is therefore named a dyad (Dowling \& Boycott, 1966). The two processes postsynaptic to cone bipolar cells are a ganglion cell dendrite and an amacrine cell process. In the case of rod bipolar

Address correspondence and reprint requests to: Heinz Wässle, MaxPlanck-Institut für Hirnforschung, Deutschordenstr. 46, D-60528 Frankfurt / Main, Germany. E-mail: Waessle@mpih-frankfurt.mpg.de cells, the two postsynaptic processes are the dendrites of two different types of amacrine cell, the AII and the AI cell (Kolb \& Famiglietti 1974; A17 cell in cats, S1/2 cell in rabbits, Li et al., 2002). Bipolar cells release glutamate and the light responses of their postsynaptic ganglion and amacrine cells depend on the type of glutamate receptors (GluRs) they express at the dyad.

Ionotropic GluRs have been subdivided into three major classes: a-amino-3-hydroxy-5-methylisoxazole-4-proprionic acid (AMPA), kainic acid (KA), and N-methl-d-aspartate (NMDA) receptors. Molecular cloning has shown that AMPA receptors are complexes of the subunits GluR1, GluR2, GluR3, or GluR4. KA receptors are composed of the subunits GluR5, GluR6, GluR7, KA-1, or KA-2 and NMDA receptors are composed of the subunits NR1, NR2A, NR2B, NR2C, NR2D, and NR3A. In addition, the orphan receptor subunits $\delta 1$ and $\delta 2$ are associated with these GluRs (Hollmann \& Heinemann, 1994; Ozawa et al., 1998; Dingledine et al., 1999; Kew \& Kemp, 2005).

The localization of GluRs in the retina was first studied at the mRNA level by in situ hybridization (Hughes et al., 1992; Müller et al., 1992; Zhang et al., 1996). All three classes of GluRs were 
observed in the amacrine cell layer; however, the resolution of the signals was not sufficient to distinguish different amacrine cell types.

Immunocytochemical staining of the retina with subunit specific antibodies has revealed a clustering of GluRs in postsynaptic densities. The clusters immunostained for the different subunits show characteristic distributions across the inner plexiform layer (IPL), suggesting they are involved with different sets of neurons (Hartveit et al., 1994; Peng et al., 1995; Brandstätter et al., 1998; Thoreson \& Witkovsky, 1999; Fletcher et al., 2000; Hack et al., 2001; Grünert et al., 2002). The two postsynaptic partners at the bipolar cell dyad usually express two different types of GluRs (Brandstätter et al., 1994; Qin \& Pourcho, 1996, 1999a,b; 2001). A more detailed analysis has been performed examining the GluRs postsynaptic to the rod bipolar cell dyad showing that AMPA receptors are localized to the AII cell, while $\delta 1 / 2$ subunits are found on the A17 cell (Ghosh et al., 2001; Li et al., 2002).

Marc $(1999 a, b)$ and Kalloniatis et al. (2004) have studied the glutamatergic drive of different neurons in the retina with a channel-permeant guanidinium analogue (1-amino-4-guanidobutane, AGB) and observed strong NMDA activation in only a subset of amacrine cells. GABAergic amacrine cells displayed a range of $\mathrm{KA}$ responses, whereas glycinergic amacrine cells were all driven by KA.

Previously, electrophysiological characterization of the GluRs expressed by amacrine cells has been hampered by a lack of specific agonists and antagonists of AMPA and KA receptors (Wilding \& Huettner, 1995), allowing differentiation only between NMDA and non-NMDA receptors. These studies showed that NMDA receptors play only a minor role in the light responses of AII, A17, and starburst amacrine cells (Boos et al., 1993; Zhou \& Fain, 1995; Hartveit \& Veruki, 1997). Recently, the availability of selective drugs such as cyclothiazide (Vyklicky et al., 1991; Bertolino et al., 1993; Palmer \& Lodge, 1993), GYKI 52466 and GYKI 53655 (Donevan \& Rogawski, 1993; Wilding \& Huettner, 1995; Bleakman et al., 1996) and SYM 2081 (Gu et al., 1995; Zhou et al., 1997; Donevan et al., 1998) allows differentiation between AMPA and KA receptors. Recordings from AII amacrine cells showed that the functional non-NMDA GluRs of AII amacrine cells were exclusively AMPA receptors (Mørkve et al., 2002; Veruki et al., 2003; Zhou \& Dacheux, 2004). Paired recordings from rod bipolar and AII amacrine cells as well as from rod bipolar and A17 cells demonstrated that the signal transfer is mediated by AMPA receptors (Singer \& Diamond, 2003). It is still a matter of debate, whether AII amacrine cells also express NMDA receptors and what their functional roles might be (Boos et al., 1993; Hartveit \& Veruki, 1997; Trexler et al., 2003; Zhou \& Dacheux, 2004).

Taken together, the results from anatomy and physiology suggest that different amacrine cells signal through specific GluRs or combinations of GluRs. However, there is a mismatch between the physiological and anatomical results for KA and AMPA receptors. The aim of this paper was to further characterize the ionotropic GluRs expressed by amacrine cells. Whole-cell recordings were performed on slices of mouse retina and the pharmacological sensitivity of AMPA-, KA-, and NMDA-elicited currents was investigated. During recordings, cells were filled with a fluorescent marker to reveal their morphology. Some experiments were performed on retinal slices from a transgenic mouse, in which enhanced green fluorescent protein (EGFP) was expressed under the control of the glycine transporter GlyT2 (Zeilhofer et al., 2005), in order to selectively target different amacrine cell types.

\section{Materials and methods}

Preparation of retinal slices, visualization, and identification of amacrine cells

Wild-type (C57B16) and transgenic mice, aged 5-8 weeks, were used for the experiments. The transgenic mouse line carries the gene for green fluorescent protein (EGFP) driven by the GlyT2 promotor (Zeilhofer et al., 2005). The mice were deeply anesthetized with isoflurane (CuraMED Pharma GmbH, Karlsruhe, Germany) and decapitated. All procedures were approved by the local animal care committee and were in accordance with the law for animal experiments issued by the German Government (Tierschutzgesetz). The retinae were dissected free from the eyecup in Ames solution (Sigma-Aldrich, Taufkirchen, Germany) and were embedded in $2 \%$ agar dissolved in Ames medium (kept at $38^{\circ} \mathrm{C}$ ). The resulting block was rapidly cooled and transferred to a microslicer (Dosaka EM Co., Japan). 200- $\mu$ m-thick slices were cut, which were then kept in Ames equilibrated with carbogen $\left(95 \% \mathrm{O}_{2}\right.$ and $5 \% \mathrm{CO}_{2}$ ) for $30 \mathrm{~min}$ before electrophysiological recording. The tissue could be maintained for up to $6 \mathrm{~h}$ in oxygenated Ames medium. The specimens were viewed by differential interference contrast (DIC) microscopy using a water immersion objective $(63 \times$, Zeiss, Oberkochen, Germany) on a fixed stage, upright microscope (Axioskop, Zeiss).

The experiments were done under laboratory light conditions, and consequently the retina was light adapted. In some cases the photoreceptors were bleached, because of the epifluorescence illumination used to find and patch EGFP-positive amacrine cells (filter set Nr. 09; Zeiss, Oberkochen). In general, to record from amacrine cells, we patched somata in the inner part of the inner nuclear layer (INL).

\section{Solutions and chemicals}

The recording chamber was perfused at a rate of $\sim 2 \mathrm{ml} / \mathrm{min}$ with bicarbonate-buffered carbogenated Ames solution (Sigma-Aldrich, Taufkirchen, Germany). The intracellular solution contained in $\mathrm{mM}$ : Cs-gluconate 125.0, $\mathrm{CaCl}_{2}$ 1.0, EGTA 10.0, $\mathrm{MgSO}_{4} 4.6$, Na-Hepes 10.0, NaATP 4.0, NaGTP 0.4, tetrabutylammonium (TBA) 5.0, Neurobiotin (Vector Laboratories, Burlingame, CA) 10.0, Lucifer Yellow (LY) or Alexa488 (Molecular Probes, Göttingen, Germany) $0.1, \mathrm{pH}=7.42$ adjusted with $5.9 \mathrm{M} \mathrm{CsOH}$. All transmitter agonists and antagonists were applied by local superfusion through a multibarrel, pressure-driven system (DAD12, ALA Scientific Instruments, Lambrecht, Germany) with a final tip diameter of $100 \mu \mathrm{m}$. The tip was placed $\sim 50 \mu \mathrm{m}$ from the cell. Hepesbuffered solution, used in the application system, contained in $\mathrm{mM}$ : $\mathrm{NaCl} 145, \mathrm{KCl} 2.5, \mathrm{CaCl}_{2} 2.0, \mathrm{MgCl}_{2}$ 1.0, Na-Hepes 1.0, $\mathrm{pH}=7.4$ adjusted with $1 \mathrm{M} \mathrm{NaOH}$. For brevity, it will be called DAD solution for the rest of the manuscript. Puffing control solution alone did not evoke any currents. The liquid junction potential between intracellular and extracellular solutions was calculated to be $15 \mathrm{mV}$ and was later subtracted from the raw data (Liquid junction potential calculator; Barry, 1994).

The drugs were prepared as stock solutions, in mM: glycine 1, AMPA 10, KA 25, NMDA 50, NBQX 5, cyclothiazide 10, D-AP5 100 (Biotrend Tocris, Cologne, Germany), GYKI 5246610 (SigmaAldrich), GYKI 5365510 (kind gift of Dr. Carl Romano, Washington University, St. Louis, MS), SYM 208110 (Calbiochem, Bad Soden, Germany), strychnine 1 (Sigma-Aldrich). For each experiment the drugs were freshly dissolved in filtered DAD solution. All other chemicals were purchased from Sigma-Aldrich. 


\section{Patch-clamp recordings}

Recordings were carried out at room temperature with an EPC-9 patch-clamp amplifier (HEKA Electronik, Lambrecht, Germany) and Pulse 8.11 software. The patch pipettes were pulled from borosilicate glass tubing (Hilgenberg, Malsfeld, Germany). When filled with internal solution, they had a resistance of 7-9 M $\Omega$. Cells were voltage-clamped in the whole-cell mode. Input resistances were $\sim 1 \mathrm{G} \Omega$. Series resistances were $\sim 20 \mathrm{M} \Omega$ and were left uncompensated in most of the recordings. The cell and pipette capacitances were cancelled. The signals were filtered using the eight-pole Bessel filter built-in to the EPC-9 amplifier and digitized at a frequency of $0.5 \mathrm{kHz}$, which was at least twice the filter cutoff frequency.

\section{Experimental protocols and data analysis}

Cells were voltage clamped at $-75 \mathrm{mV}$, which is close to the resting potential of most amacrine cells. Non-NMDA GluRs were activated by application of the basic agonists AMPA and KA. In the present study, 100 or $200 \mu \mathrm{M}$ of agonist were used, close to the reported $\mathrm{EC}_{50}$ values in AII cells of the rat retina: $118 \mu \mathrm{M}$ for AMPA and $169 \mu \mathrm{M}$ for KA (Mørkve et al., 2002). AMPA- and KA-induced currents were blocked by the nonselective nonNMDA antagonist NBQX (Sheardown et al., 1990; Lodge et al., 1991), applied at a concentration of $10 \mu \mathrm{M}$. Discrimination of AMPA from KA receptor-mediated responses was made using the selective AMPA receptor antagonists GYKI 52466 and GYKI 53655, the allosteric AMPA receptor modulator cyclothiazide (CTZ) and the KA receptor agonist SYM 2081. CTZ is known to remove the rapid desensitization at AMPA receptors and thus increase the AMPA response, while also prolonging its decay time (Vyklicky et al., 1991; Bertolino et al., 1993; Palmer \& Lodge, 1993). SYM 2081 is a KA receptor-selective agonist, with antagonist-like ef- fect, which limits transmission at KA receptors by producing a brief activation followed by a maintained desensitization (Zhou et al., 1997; Donevan et al., 1998). Finally, GYKI 52466 and GYKI 53655 selectively inhibit the activity of AMPA receptors (Donevan \& Rogawski, 1993; Wilding \& Huettner, 1995; Bleakman et al., 1996). Drugs were applied from a twelve-line superfusion system, through an application pipette with a diameter of $100 \mu \mathrm{m}$. The applications followed a standard sequence: basic agonist-basic agonist with selective agonist/antagonist-basic agonist (selective agonist/antagonist wash-out). A thirteenth flush line, active between applications, ensured the removal of any previous drug left in the pipette tip before a new application. The time between applications ranged from $1.5 \mathrm{~min}$ to $2 \mathrm{~min}$, to allow for receptor recovery from possible desensitization. Each sequence of drug applications was repeated several times to make sure that the effects were reproducible. Data analysis was subsequently carried out with IgorPro 4 (WaveMetrics Inc., Lake Oswego, OR) using homemade routines and the statistics and graphs were completed in Excel (Microsoft).

Expression of NMDA, AMPA, and KA receptors was determined by analyzing the effects of the receptor-selective drugs on the current induced by the basic agonist. Agonist-induced currents were integrated over time resulting in total charge transported through the cell membrane. The charge transfers during the action of the agonist and the different antagonists were normalized to the control values and compared.

\section{Light microscopy}

The cells expressing EGFP under the GlyT2 promoter were investigated in sections that were immunolabeled for GABA (Sigma, Taufkirchen, Germany), 1:2000, rabbit anti GABA, and for the glycine transporter GlyT1 (Chemicon, Temecula, CA) 1:5000, goat anti GlyT1. Standard immunocytochemical methods were
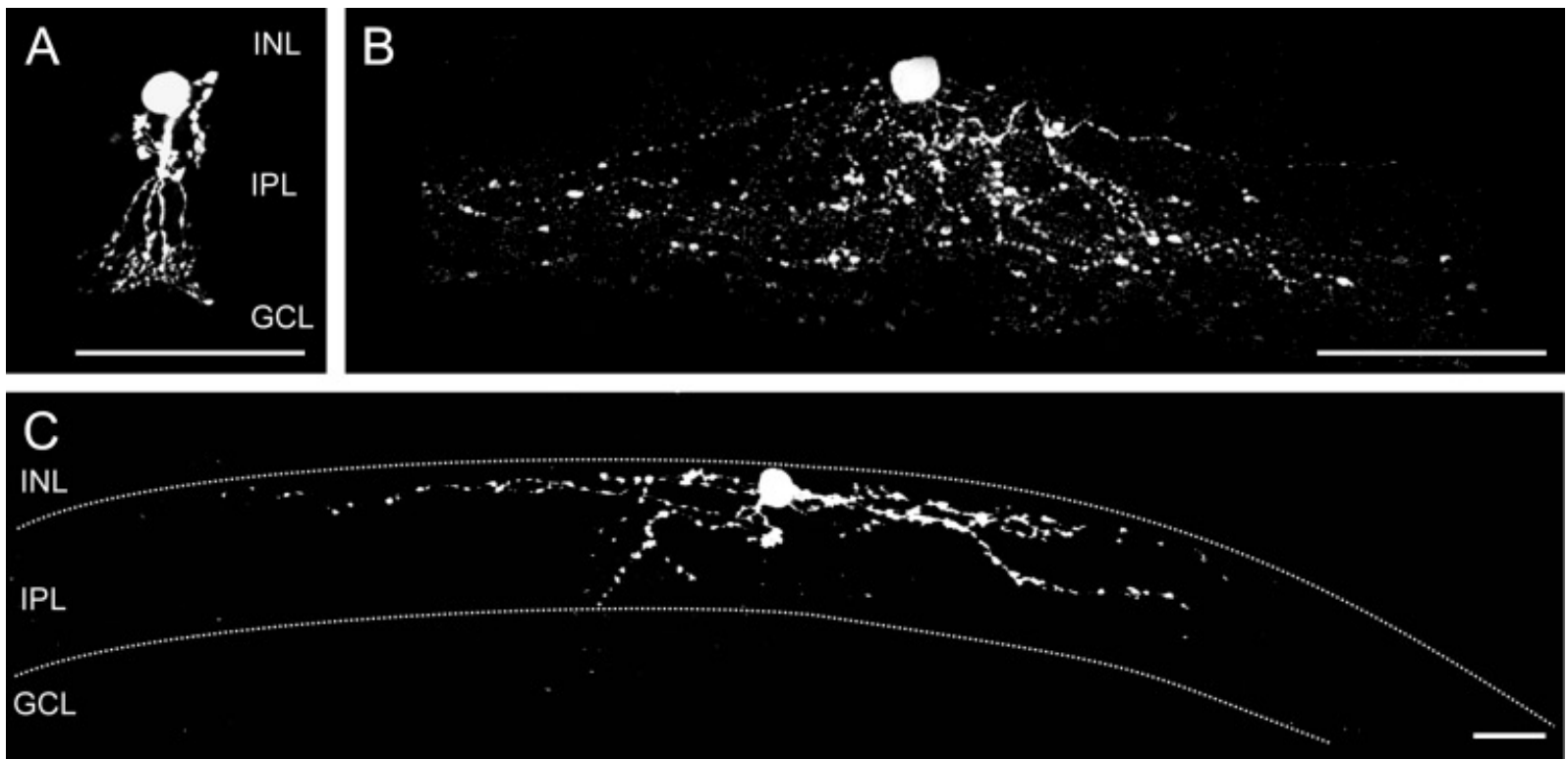

Fig. 1. Morphological identification of the recorded amacrine cells. A, typical AII amacrine cell with lobular dendrites in the outer part of the inner plexiform layer (IPL) and arboreal dendrites in the inner IPL. B, typical A17 cell with many long and fine dendrites that descend into the inner IPL. The dendrites are decorated with numerous varicosities. C, stratified, wide-field amacrine cell with a dendritic arbor mostly confined to the outer IPL (INL: inner nuclear layer; IPL: inner plexiform layer; and GCL: ganglion cell layer; scale bars $=20 \mu \mathrm{m}$ ). 
used (Haverkamp et al., 2004). The slices with LY or Alexa488and Neurobiotin-filled cells were fixed for $30 \mathrm{~min}$ with $4 \%$ paraformaldehyde in $0.1 \mathrm{M}$ phosphate buffer $(\mathrm{PB})$ at room temperature and washed in phosphate buffer (PB) several times. Neurobiotin was visualized using Streptavidin Alexa488 (1:2000; Molecular Probes, Göttingen, Germany). The slices were mounted on a slide and examined on a confocal laser scanning microscope (Zeiss LSM Pascal) using a $40 \times$ oil immersion objective. Stacks of confocal images were projected onto a single image plane. The size and contrast of the images were adjusted using Adobe Photoshop (Version 7.0).

\section{Results}

\section{Anatomical characterization of amacrine cells}

Whole-cell recordings were made from amacrine cells in vertical slices of the mouse retina. The slices were viewed using DIC optics and in the majority of the recordings the electrode was directed to the cell bodies of amacrine cells in the INL without prelabeling them. The electrode was filled with LY and Neurobiotin or with Alexa488 and Neurobiotin, which diffused into the cells during the recordings. After the experiments, the injected cells were visualized with fluorescent streptavidin and photographed on a confocal microscope. Given that there are 30 different types of amacrine cells, it was not possible to unequivocally identify the cells a priori in the slices. This was only possible for AII amacrine cells (Fig. 1A), while the remaining cells were grouped into narrow-field and wide-field cells. One wide-field cell, a putative A17 cell, is illustrated in Fig. 1B, a second wide-field cell with stratified dendrites is shown in Fig. 1C.

In later experiments, a transgenic mouse line in which EGFP is expressed in amacrine cells under the control of the GlyT2 promoter, was used (Zeilhofer et al., 2005). Many amacrine cell bodies and their processes in the IPL showed strong expression of EGFP (Fig. 2) (Haverkamp et al., 2004), which was unexpected, because previous immunocytochemical studies had shown that glycinergic amacrine cells express GlyT1 but not GlyT2 (Zafra et al., 1995; Menger et al., 1998). In order to study the amacrine cell types expressing EGFP in the transgenic mice, we double labeled sections for EGFP and GlyT1 (Figs. 2A \& 2B) and found that $85 \%$ of the EGFP-labeled amacrine cells also express GlyT1. We also double labeled sections for EGFP and GABA (Figs. 2C \& 2D) and observed $15 \%$ double-labeled cell bodies (arrowheads in Figs. 2C \& 2D). It was relatively easy to target the recording electrode to AII amacrine cells in the EGFP transgenic mice, because their primary dendritic trees were visible under fluorescence illumination (Fig. 2E). In order to record GABAergic amacrine cells, we directed the electrode to cell bodies that did not express EGFP. For the recordings of glycinergic amacrine cells, EGFP-labeled cell bodies were recorded and filled with Alexa488. If they were small-field amacrine cells, they were classified as glycinergic amacrines.

\section{AMPA- and KA-evoked currents of amacrine cells}

Whole-cell currents were recorded from amacrine cells which were voltage clamped at $-75 \mathrm{mV}$. Non-NMDA GluRs were activated by the application of AMPA and KA from a puffer pipette. Fig. 3A shows KA-induced currents of an amacrine cell at different holding potentials. The currents reversed at $0.7 \pm 5 \mathrm{mV}$ and a current-voltage plot shows a linear relationship (Fig. 3B).
Both AMPA- (Figs. 3C-3E) and KA-evoked currents (Figs. 3F$3 \mathrm{H})$ could be reversibly blocked by the co-application of $10 \mu \mathrm{M}$ NBQX. The linear current-voltage relation and their complete blockade by NBQX indicate that these currents are mediated by non-NMDA receptors.

For a more detailed analysis, cells were probed as shown in Fig. 4. First AMPA was applied on its own (Fig. 4A), next AMPA was applied together with CTZ (Fig. 4B) followed again by AMPA alone (Fig. 4C). The AMPA-evoked current was increased and prolonged during the CTZ application suggesting that this cell expresses AMPA receptors. The same cell was further probed with KA (Figs. 4D-4F). Application of KA induced a strong inward current that could be effectively blocked by the co-application of GYKI 52466, the selective AMPA receptor antagonist. In contrast, when KA was co-applied together with SYM 2081, the selective KA receptor agonist, no current changes could be observed with respect to the control (Figs. 4G-4I). Finally, SYM 2081 was applied on its own (Fig. 4J) and no current was induced. Taken together these results suggest that the GluRs expressed by this amacrine cell are AMPA and not KA receptors.

We also found cells which preferentially expressed KA receptors (Fig. 5). First, AMPA was applied (Fig. 5A), followed by AMPA together with CTZ (Fig. 5B) and the control (Fig. 5C). CTZ had only little effect on the AMPA-induced response. Next, the cell was probed with KA (Fig. 5D) and KA together with GYKI 52466 (Fig. 5E) followed by the control (Fig. 5F). GYKI was not able to block or even reduce the KA-evoked current. Finally, the selective KA receptor agonist SYM 2081 was tested (Figs. 5G-5I), occluding most of the KA-induced current (Fig. 5H). SYM 2081 applied alone induced a small inward current. Amacrine cells showing this pharmacological profile were considered to express KA but not AMPA receptors.

In most amacrine cells, we observed mixed responses, partially mediated by AMPA and partially by KA receptors. Such a cell is illustrated in Fig. 6. The current elicited by the application of AMPA (Fig. 6A) is greatly enhanced by the co-application of CTZ (Fig. 6B). The AMPA-induced current is also greatly reduced by the application of GYKI 52466 (Fig. 6E). Both results suggest activation of AMPA receptors in this cell. Interestingly, when KA was applied (Figs. 6G-6I), co-application of SYM 2081 did not cause much reduction of the peak current although a faster deactivation was observed and the total charge transfer was reduced by 23\% (Fig. 6H). This reduction was completely reversible (Fig. 6I). In addition, application of SYM 2081 alone elicited a small inward current (Fig. 6J). These results suggest that this cell also expresses KA receptors. The recordings shown in Fig. 6 also indicate that a more quantitative definition of the AMPA/KA pharmacology is needed.

In recent studies of the retina, GluRs could be separated into AMPA and KA subtypes (Shen et al., 1999; DeVries, 2000; Mørkve et al., 2002; Singer \& Diamond, 2003; Veruki et al., 2003; Shen et al., 2004). Paired recordings from cones and OFF cone bipolar cells enabled DeVries to study the pharmacological profiles of AMPA and KA receptors separately in different bipolar cells. Shen and coworkers (2004) studied the GluR of cultured human horizontal cells and found that they express both AMPA and KA receptors.

In this study, the expression of AMPA receptors was assumed when the following two conditions were fulfilled: (1) the total charge transported following application of AMPA was increased to $125 \%$ or more during the co-application of CTZ; (2) the total charge transported by the application of KA was reduced by the 

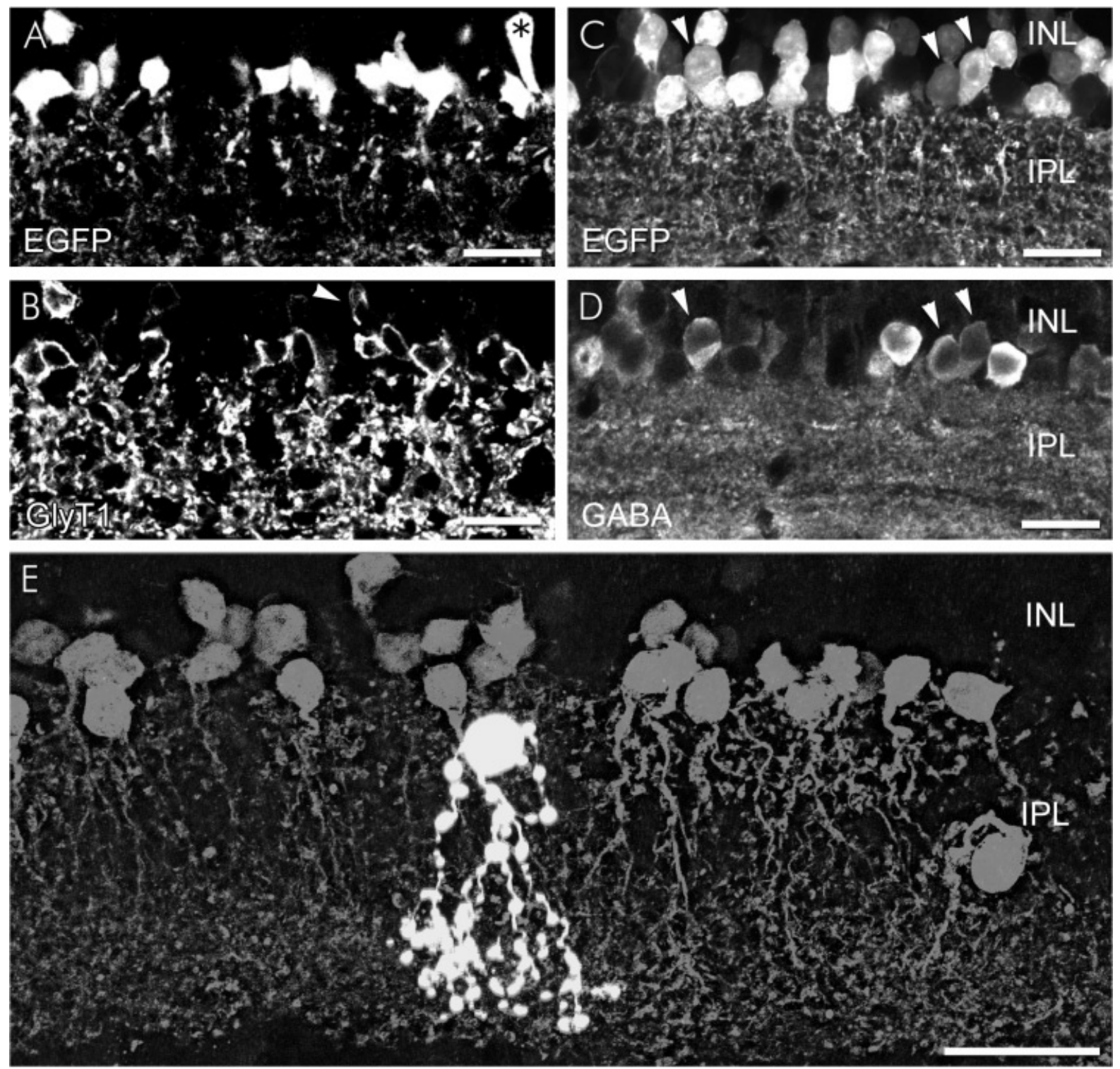

Fig. 2. Expression of enhanced green fluorescent protein (EGFP) in amacrine cells under the control of the glycine transporter GlyT2 promoter. A and B show for the same section the EGFP expression (A) and GlyT1 immunolabeling (B). The great majority of amacrine cells are double labeled. However, the cell marked by an asterisk in A is not labeled in B and the cell indicated by the arrowhead in B is not labeled in A. C and D show the same section double labeled for EGFP (C) and GABA (D). Some of the EGFP labeled cells also express GABA (arrowheads). E, expression of EGFP in amacrine cells (grey) and an intracellularly injected AII amacrine cell (white). The micrograph shows a collapsed stack of confocal sections through a slightly oblique retinal slice. The brightness and contrast of the injected AII cell had to be increased to improve its visibility with respect to the EGFP labeled cells of the background. For that reason the AII dendrites appear thicker and more varicose than usually. Conventions are as in Fig. 1. Scale bars $=20 \mu \mathrm{m}$.

co-application of GYKI 52466 to less than $75 \%$ or by GYKI 53655 to less than $85 \%$. The expression of KA receptors was assumed when the following two conditions were fulfilled: (1) more than $25 \%$ of the total charge transported at the application of KA were left during the co-application of GYKI 52466 or 53655; (2) less than $90 \%$ of the total charge transported at the application of KA were left during the co-application of SYM 2081.

Based on these criteria, the expression of AMPA and KA receptors by the different amacrine cell types recorded in this study followed the pattern illustrated in Fig. 7. The majority (77\%) of AII amacrine cells tested $(n=13)$ expressed AMPA and KA receptors whilst $23 \%$ of them exclusively expressed AMPA receptors. No AII cells were found to express only KA receptors.

In the case of narrow-field amacrine cells $(n=27)$ (Fig. 7, $\mathrm{NF}), 70 \%$ were found to express both AMPA and KA receptors, in $7 \%$ only AMPA receptors were found, while in $22 \%$ KA receptors were observed exclusively.

In the case of wide-field amacrine cells $(n=14)$ (Fig. 7, WF), only $43 \%$ were found to co-express AMPA and KA receptors, $36 \%$ expressed solely AMPA, and $21 \%$ only KA receptors.

As described above, the amacrine cells recorded in the GlyT2EGFP transgenic mouse retina were subdivided into glycinergic 
A

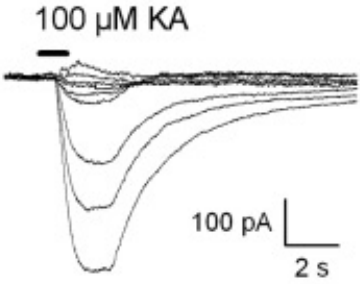

B

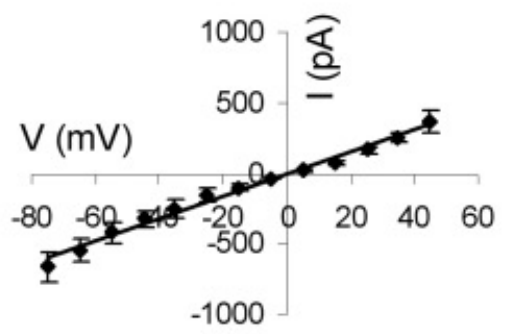

C

$100 \mu \mathrm{M}$ AMPA

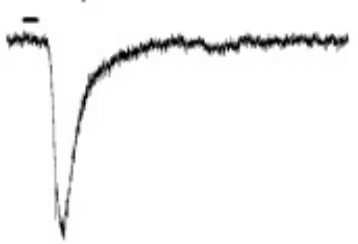

F

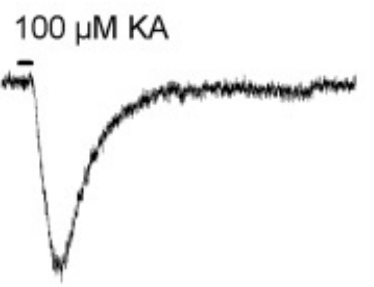

D

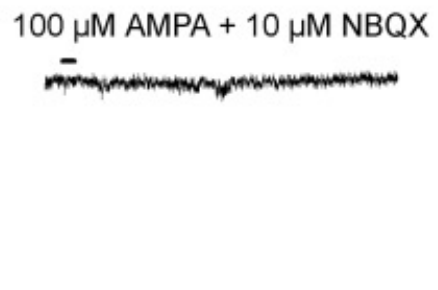

G

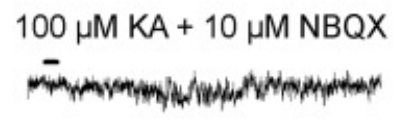

E

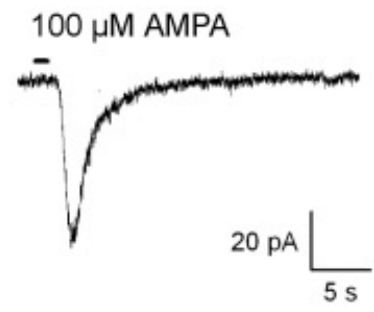

$\mathrm{H}$

$100 \mu \mathrm{M}$ KA

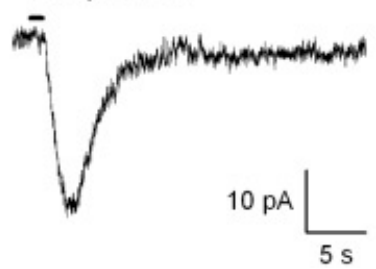

Fig. 3. AMPA- and KA-evoked currents of an amacrine cell. A, currents evoked by the application of KA at different holding potentials. In this and all following graphs, the horizontal bar represents the time during which the drugs were ejected from the puffer pipette. $\mathrm{B}$, current-voltage relation of KA-evoked currents (average of 7 cells). C, current evoked by the application of AMPA. D, coapplication of AMPA and NBQX blocked this current. E, recovery. F, current evoked by the application of KA. G, co-application of KA and NBQX blocked this current. H, recovery.

and GABAergic cells (Fig. 7, GLY and GABA). Of the GABAergic cells $(n=6), 67 \%$ expressed AMPA as well as KA receptors, while $33 \%$ exclusively expressed KA receptors. Similarly, $81 \%$ of the glycinergic cells $(n=16)$ expressed AMPA as well as KA receptors, while $19 \%$ exclusively expressed KA receptors.

The relative contributions of AMPA and KA receptors to the total response varied among the different amacrine cell types. Fig. 8 shows the reduction of the KA-induced currents by the co-application of GYKI 52466. In the case of AII cells, the total charge transported was reduced to an average of $50 \pm 4 \%(n=5)$ and showed little variation among the cells (Fig. 8A). In the case of narrow-field amacrine cells the reduction was to $70 \pm 26 \%(n=$ 15 ) and there was much variation between the cells (Fig. 8B). In wide-field amacrine cells, the average reduction was to $51 \pm 24 \%$ $(n=11)$ and the variation between the cells was substantial (Fig. 8C).

\section{NMDA-evoked currents of amacrine cells}

We also tested amacrine cells for expression of NMDA receptors (Fig. 9). The cells were clamped to $-75 \mathrm{mV}$ and NMDA was applied at a concentration of 100 or $500 \mu \mathrm{M}$ in the presence of small amounts of the co-agonist glycine $(2 \mu \mathrm{M})$ and strychnine (1 $\mu \mathrm{M})$, to prevent activation of glycine receptors. The $\mathrm{Mg}$ concentration of the bath solution was $1.2 \mathrm{mM}$, however, in the puffer pipette solution no $\mathrm{Mg}$ was included in order to reduce the Mg-block of NMDA receptors at hyperpolarizing potentials. Under these circumstances, small responses (Fig. 9C), which were reversibly blocked by the co-application of AP5 (Figs. 9D \& 9E), could be observed. When the NMDA-evoked currents were measured at different holding potentials (Fig. 9A), they showed the typical nonlinear current-voltage relation of NMDA receptors (Fig. 9B). This indicates that partial magnesium block of the NMDA receptors remained. NMDA-evoked currents could not be blocked by the application of NBQX (Figs. 9F-9H). In accordance with this, AMPA- and KA-induced currents could not be blocked by AP5 (Figs. 9I-9K).

In all cells tested, the NMDA-evoked currents were significantly smaller than the AMPA- and KA-evoked responses. However, they might have been underestimated when recording at -75 $\mathrm{mV}$, because of the incomplete removal of the $\mathrm{Mg}^{2+}$ blockade (Fig. 9B). Even at depolarizing potentials their amplitudes reached 


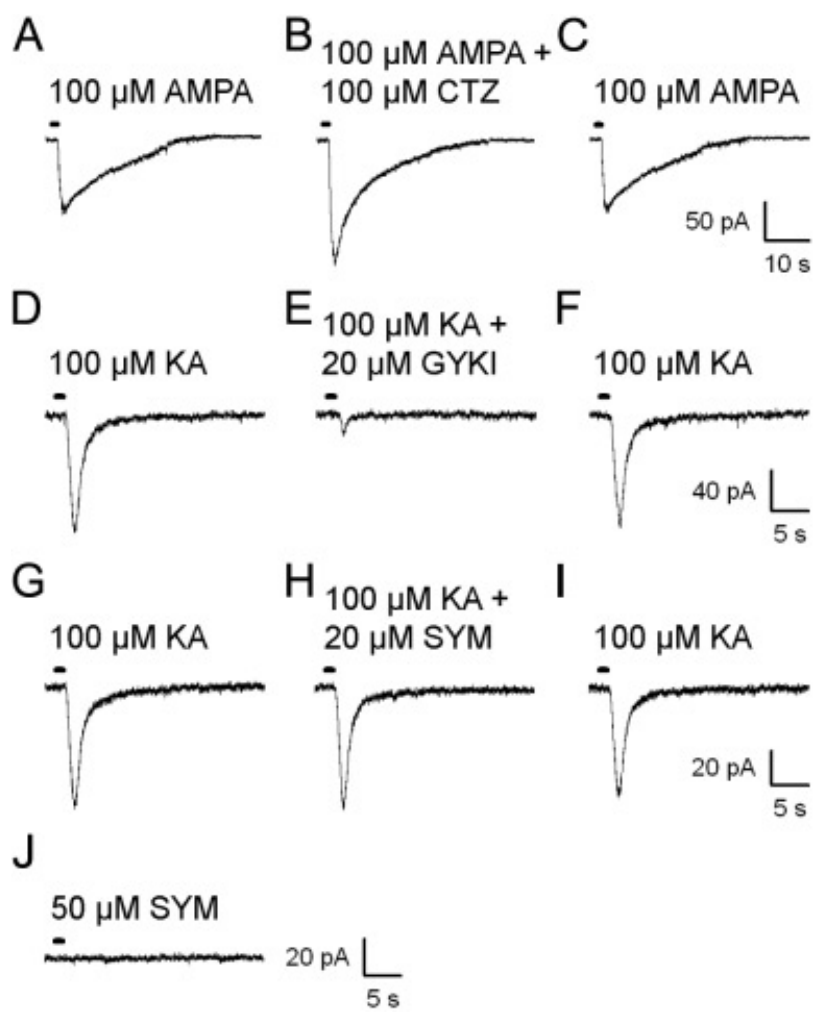

Fig. 4. Wide-field amacrine cell expressing only AMPA receptors. A, inward current induced by the application of AMPA. B, co-application of AMPA and cyclothiazide (CTZ) increased the current. C, recovery. D, inward current induced by the application of KA. E, co-application of KA and GYKI 52466 (GYKI) effectively blocked the current. F, recovery. $\mathrm{G}$, inward current induced by the application of KA. H, co-application of KA and SYM 2081 (SYM) did not change the current. I, recovery. $\mathrm{J}$, application of SYM alone had no effect.

$80 \mathrm{pA}$ in the best cases. We have not encountered any cells that exclusively express NMDA receptors. Application of $100 \mu \mathrm{M}$ NMDA elicited small responses in most wide-field and half of the narrow-field amacrine cells tested, but no AII amacrine cells showed NMDA-mediated currents under these conditions. When the concentration of NMDA was increased to $500 \mu \mathrm{M}$ and the holding potential switched to depolarized values ( 35 to $45 \mathrm{mV}$ ), NMDA responses could be measured in most wide-field, in about half of the narrow-field cells, and in 3 out of 12 AII amacrine cells.

These results are illustrated in more detail in the summary diagram in Fig. 10. There appears to be a difference with respect to the expression of NMDA receptors among the cell populations investigated: the majority of wide-field amacrine cells (WF, GABA in Fig. 10) express NMDA receptors, while less than half of the narrow-field amacrine cells (AII, NF and GLY in Fig. 10) show NMDA responses.

\section{Discussion}

Are there amacrine cells that express exclusively AMPA or KA receptors?

It has been shown for OFF cone bipolar cells that two types (b3, b7) express exclusively KA receptors at their cone contacts, while

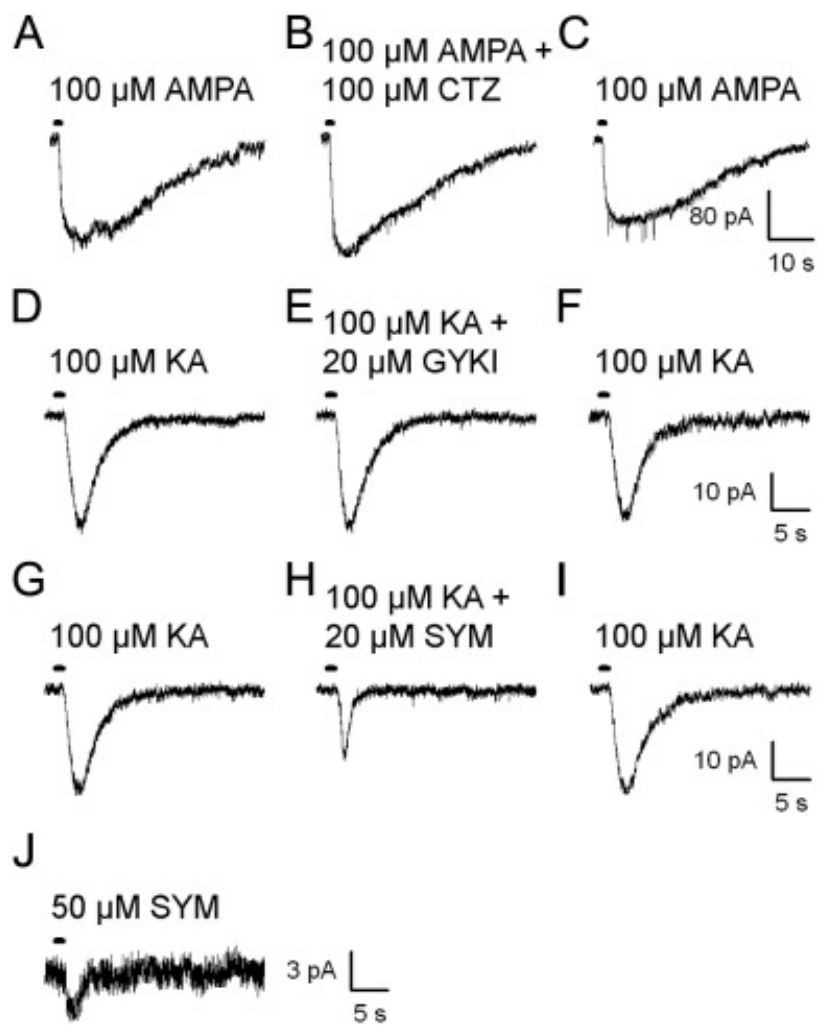

Fig. 5. Narrow-field amacrine cell expressing only KA receptors. A, inward current induced by the application of AMPA. B, co-application of AMPA and CTZ did not significantly change the current. C, recovery. D, inward current elicited by the application of KA. E, co-application of KA and GYKI did not change the current. F, recovery. G, inward current elicited by the application of KA. H, co-application of KA and SYM strongly reduced the current. I, recovery. J, SYM application of SYM alone induced a small current.

one type (b2) receives its cone input only via AMPA receptors (DeVries, 2000). In the case of horizontal cells, it was found that they express both AMPA and KA receptors (Shen et al., 2004). Because of the high number of different amacrine cell types the encounter rate of a given type was very low. Some of the amacrine cell types make up less than $1 \%$ of the amacrine population and, therefore, might not have been recorded from at all in our study. Nonetheless we observed convincing examples of cells that expressed exclusively AMPA (Fig. 4) or KA receptors (Fig. 5). Such cells were more often found amongst the population of wide-field cells. Because of the high number of different amacrine cells, we could only study their GluRs by puffing agonist and it is difficult to asign synaptic roles to the receptors mediating the puff-evoked responses. Clearly, studies of spontaneous synaptic currents (sEPSCs) and of paired recordings of presynaptic and postsynaptic neurons are the method choice for a more detailed analysis of synaptic receptors (Mørkve et al., 2002; Veruki et al., 2003; Singer \& Diamond, 2003).

The synaptic localization of both AMPA and KA receptors in the IPL has also been studied by immunocytochemical methods in the rodent, cat, and primate retina. All four AMPA subunits (GluR1-4) have been described in postsynaptic processes of bipolar cell dyads. Usually only one of the two postsynaptic processes expressed AMPA receptors (Qin \& Pourcho, 1996, 1999a,b; 


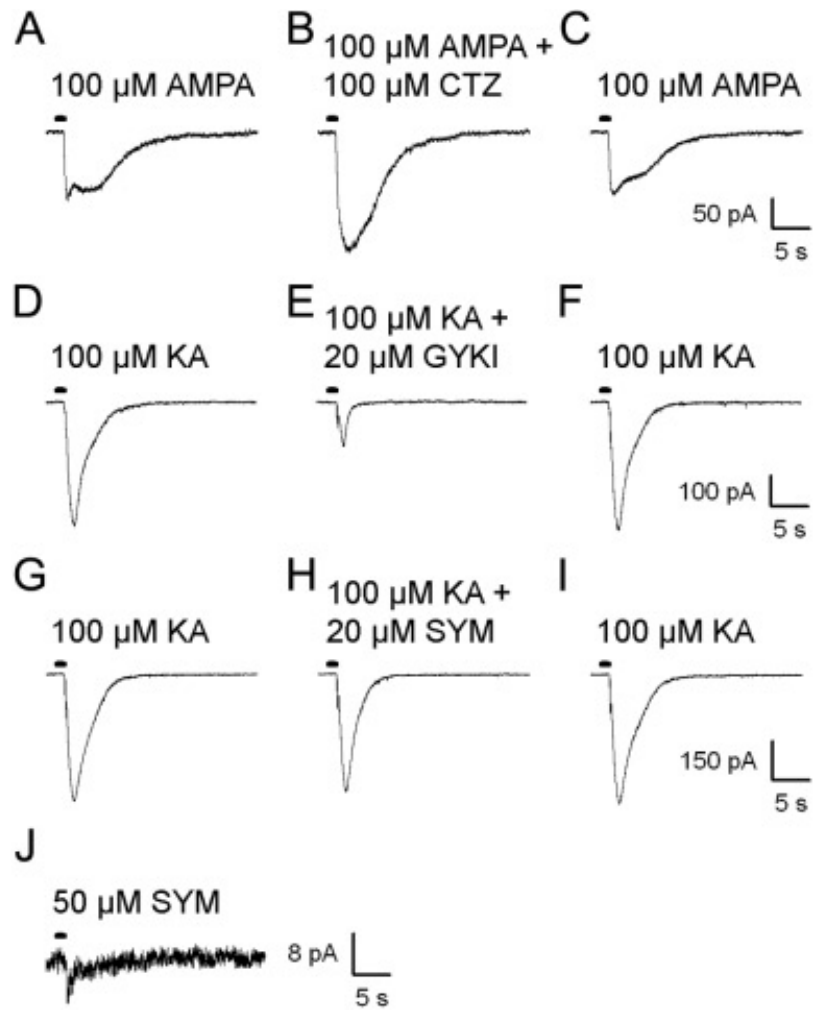

Fig. 6. Narrow-field amacrine cell expressing both AMPA and KA receptors. A, inward current elicited by the application of AMPA. B, coapplication of AMPA and CTZ enhanced the current. C, recovery. D, current induced by the application of KA. E, co-application of KA and GYKI greatly reduced the current. F, recovery. G, current induced by the application of KA. H, faster deactivation of the current during the co-application of KA and SYM. I, recovery. J, small inward current elicited by the application of SYM alone.

Grünert et al., 2002, 2003). KA receptor subunits (GluR5-7, KA1,2 ) have also been localized, postsynaptic to bipolar cells (Brandstätter et al., 1997; Qin \& Pourcho, 2001; Grünert al., 2002, 2003). Usually only one of the two postsynaptic processes expressed KA receptors. The same holds true for the $\delta$ subunits (Brandstätter

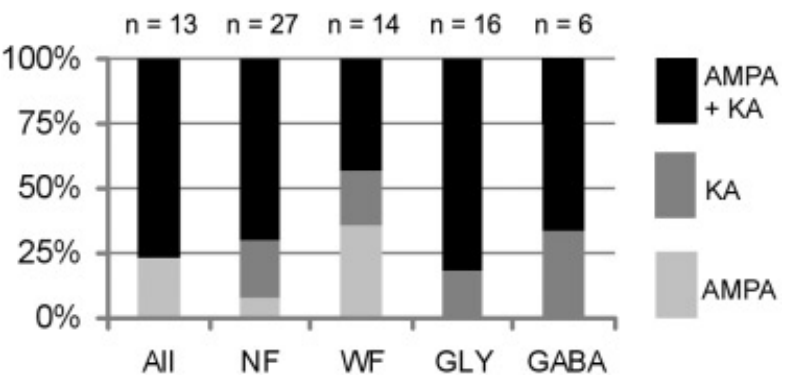

Fig. 7. Summary diagram of the expression of KA and AMPA receptors by the different amacrine cell types (AII: AII amacrine cells; NF: narrow-field amacrine cells; WF: wide-field amacrine cells; GLY: glycinergic amacrine cells; GABA: GABAergic amacrine cells). Black columns: cells express both KA and AMPA receptors. Dark grey columns: cells express only KA receptors. Light grey columns: cells express only AMPA receptors. The number of cells investigated is shown on top $(n)$. et al., 1997) and for NMDA receptor subunits (Hartveit et al., 1994; Fletcher et al., 2000; Grünert et al., 2002).

These results predict that the two different postsynaptic processes at bipolar cell dyads express different sets of GluRs. Light microscopy studies have shown that the different GluRs have a distinctly stratified distribution across the IPL. The same holds true for the axon terminals of bipolar cells (Grünert et al., 2003) and the processes of many amacrine cell types.

All this, together with our findings predicts a selective wiring between bipolar cells and amacrine cells and also a specific expression of GluRs at the dyads. More work is needed, however, before the functional role of such specific expression of GluRs by amacrine cells can be understood. One prerequisite for such experiments is that particular types of amacrine and possibly bipolar cells are pre-labeled by EGFP or other markers, so they can be selected for the recordings and the subsequent analysis of their GluRs, an approach that in our experiments proved to be very helpful.

\section{Ionotropic glutamate receptors of AII and AI amacrine cells}

Signal transmission at the rod bipolar $\rightarrow$ AII/AI dyad plays a crucial role in scotopic vision, in which AII amacrine cells mediate the direct signaling pathway, whilst AI cells play a modulatory role providing inhibitory feedback to the rod bipolar cells. Thus, it is logical to expect that these amacrine cells express glutamate receptors with different biophysical properties to sculpt both the magnitude and time course of light signals. AII cells are the most common amacrine cell type of the rodent retina (Chun et al., 1993; Lee et al., 2004) and their synaptic connections and functional roles are well established (Masland, 2001; Wässle, 2004). They have bistratified dendritic trees and receive glutamatergic input from rod bipolar cells in the inner IPL and from OFF cone bipolar cells in the outer IPL. Several physiological studies have shown that the GluRs expressed at the rod bipolar $\rightarrow$ AII cell synapse are AMPA receptors (Mørke et al., 2002; Singer \& Diamond, 2003; Veruki et al., 2003). Several immunocytochemical studies have localized the GluR2/3 and GluR4 subunits to this synapse (cat: Qin \& Pourcho, 1999b; monkey: Ghosh et al., 2001; rabbit: Ghosh et al., 2001; Li et al., 2002). The expression of kainate receptors by AII amacrine cells is less clear. Mørke et al. (2002) were able to block kainate-evoked currents of AII amacrine cells by the prolonged application of GYKI 53655 at a concentration of $100 \mu \mathrm{M}$ and concluded that ionotropic non-NMDA receptors of AII cells are exclusively of the AMPA type. However, it has been shown that GYKI 53655 at a concentration of $100 \mu \mathrm{M}$ inhibits also kainate receptors (Wilding \& Huettner, 1995). Veruki et al. (2003) recorded spontaneous glutamatergic EPSCs from AII amacrine cells and demonstrated that they could block them by the application of GYKI 53655. This does not exclude that AII amacrine cells receive synaptic input through kainate receptors. Such input might have been silent in the Veruki et al. (2003) experiment. In the present study, we observed both AMPA and kainate receptors in the majority of AII cells. O'Brien et al. (2002) have recently performed a single-cell PCR study of the GluRs of mouse AII cells and observed the message for kainate receptors in three out of eight AII cells investigated.

We suggest that kainate receptors are expressed at some of the synaptic contacts made by OFF cone bipolar cells onto the lobular appendages of AII cells in the outer half of the IPL. Veruki et al. (2003) performed paired recordings from OFF cone bipolar and 


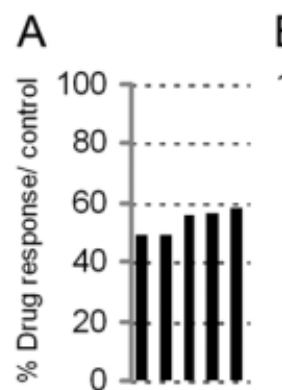

AII
B

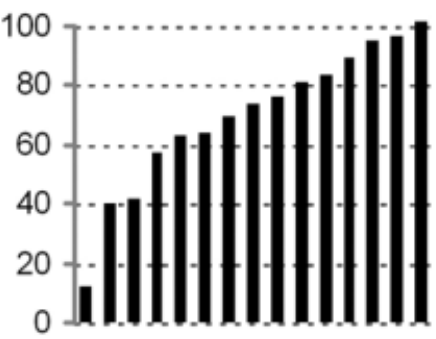

$\mathrm{NF}$
C

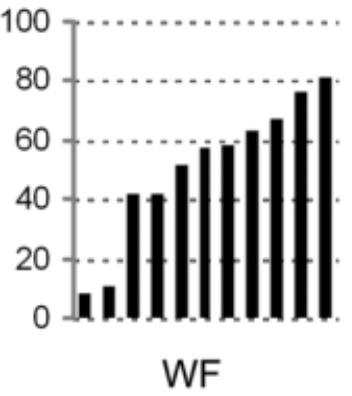

Fig. 8. Reduction of KA-induced currents of amacrine cells by the co-application of GYKI 52466. The bars represent individual cells. The ordinate shows the total charge (in percent) that was transferred during the co-application of KA + GYKI 52466 (Drug response) in relation to the charge transferred during the application of KA alone (control).
AII amacrine cells. They report that 6-cyano-7-nitroquinoxaline2,3-dione (CNQX) blocks the transmission, however, they did not study the GluRs expressed at this synapse in more detail. Habermann et al. (2001) showed that in AII cells, glutamate-induced Ca-entry occurred at the arboreal dendrites (rod bipolar input) but not at the lobular dendrites (OFF cone bipolar input). It is therefore possible that AII amacrine cells express different GluRs at these two synaptic sites. In the present study, we found that most AII cells express both AMPA and KA receptors, and it appears to be an attractive idea that AMPA receptors mediate the signal transfer from rod bipolar to AII cells, while KA receptors are involved with the signal transfer from OFF cone bipolar cells to AII cells.

Boos et al. (1993) did not observe functional NMDA receptors in rat AII cells. However, Hartveit and Veruki (1997) could elicit NMDA responses using high concentrations of NMDA $(500 \mu \mathrm{M})$ and strong depolarizing holding potentials. In the rabbit retina, Zhou and Dacheux (2004) also observed NMDA-activated currents in AII amacrine cells. NMDA receptors appear not to be involved with the rod bipolar input of AII cells (Fletcher et al., 2000; Singer \& Diamond, 2003; Veruki et al., 2003), although NMDA receptor clusters have been localized to the dendrites of AII cells in the inner IPL (Trexler et al., 2003). It was found recently that these clusters coincide with the gap junctions between AII cells (Trexler \& Massey, personal communication) and it is possible that the NMDA receptors modulate these electrical synapses.

In the case of rat AI (A17) amacrine cells, AMPA- and KAinduced currents could be blocked by CNQX (Menger \& Wässle, 2000). Furthermore, light-evoked ON-responses were also blocked by 2,3-dihydroxy-6-nitro-7-sulfamoylbenzo(f)quinoxaline (NBQX) and they were resistant to the NMDA receptor antagonist 3-(2carboxypiperazin-4-yl)propyl-1-phosphonic acid (CPP). In paired recordings from rod bipolar and AI amacrine cells, Singer and Diamond (2003) observed AMPA receptor-mediated EPSCs in the AI cells. Surprisingly, immunocytochemical studies of the rod bipolar cell dyad reported the AMPA receptor subunits GluR2/3 and GluR4 in the AII but not in the AI cells (Ghosh et al., 2001; Li et al., 2002). In contrast, the $\delta 1 / 2$ subunits were observed in AI cells. In the rabbit retina, AI cells represent two types, $\mathrm{S} 1$ and $\mathrm{S} 2$, and it was shown that only $\mathrm{S} 1$ cells express the $\delta 1 / 2$ subunits $(\mathrm{Li}$ et al., 2002). Hence, it is difficult to match the physiological results postulating AMPA receptors with the immunocytochemical results demonstrating the absence of AMPA, but suggesting the presence of other GluRs.

The diverse results regarding AII and AI cells highlight the difficulties in reconciling the pharmacological/physiological results with the molecular/immunocytochemical results. One reason might be that the pharmacological profiles of the different GluR subunits have mostly been identified in artificial expression systems (HEK 293 cells or oocytes), while in retinal neurons combinations of GluR subunits are found in postsynaptic densities that may escape such a clear cut pharmacological analysis. Nevertheless, the marked difference in the proportion of GluRs expressed by AII and WF amacrine cells reported in our study support the current view that different types of glutamate receptors are expressed at this dyadic synapse.

\section{Ionotropic glutamate receptors of cholinergic amacrine cells}

The GluRs of cholinergic amacrine cells have been studied by their release of ${ }^{3} \mathrm{H}$-acetylcholine (Linn \& Massey, 1991; Linn et al., 1991). Activation of NMDA receptors caused a massive acetylcholine (ACh) release which could be blocked by specific antagonists. However, the antagonists did not block the light- evoked release (Linn \& Massey, 1991), suggesting NMDA receptors do not mediate the physiological, light-driven input to the cholinergic amacrine cells. AMPA/KA agonists also increased the release of ACh (Linn et al., 1991) and by application of GYKI and SYM 2081 it could be shown that the predominant physiological input to cholinergic amacrine cells is mediated by AMPA receptors (Firth et al., 2003). It was also found that GluR2/3 and GluR4immunoreactive puncta coincide with the dendrites of cholinergic amacrine cells, while KA receptor subunits are absent.

The aforementioned examples of AII, AI, and cholinergic amacrine cells show that multiple GluRs are present in amacrine cells. They also show that the same amacrine cell type can express different GluRs that subserve different functions, such as the transfer of the light signal, or a more modulatory role. AII cells are the crucial interneurons in conducting the rod signal through the retina, while cholinergic amacrine cells are involved with processing information concerning moving and rapidly changing stimuli. Thus, it seems plausible that they both express the rapidly desensitizing AMPA receptors that allow the transfer of light signals with high temporal resolution.

Most other amacrine cells have more modulatory roles and are not involved with the direct transfer of the light signals. Glycinergic amacrine cells usually have narrow and vertically oriented dendritic fields. They are involved in more local operations such as interactions between the OFF- and ON-channels (Wässle, 2004). GABAergic amacrine cells are mostly wide-field cells, often narrowly stratified (in one lamina), and they are involved with spatial operations such as center-surround interactions. In the following, we will discuss how the GluR expression can be correlated with the functional roles of amacrine cells. 
A

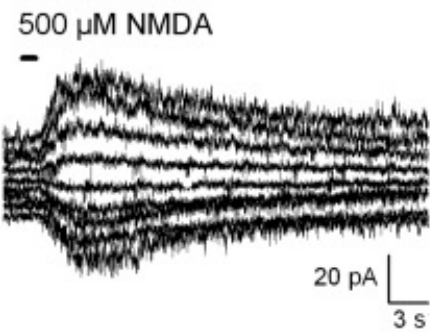

C

$500 \mu \mathrm{M}$ NMDA

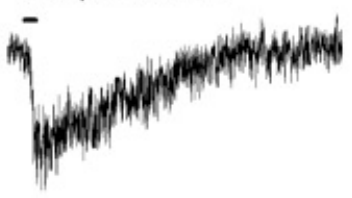

F

$500 \mu \mathrm{M}$ NMDA

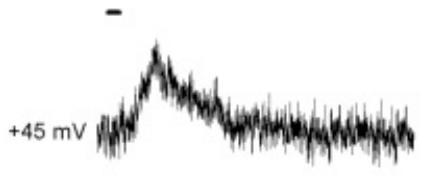

I

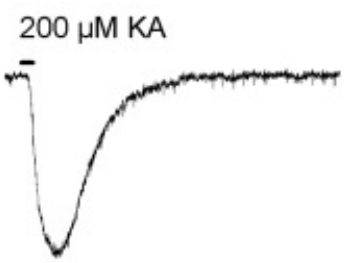

D

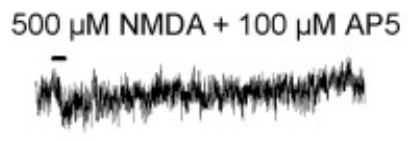

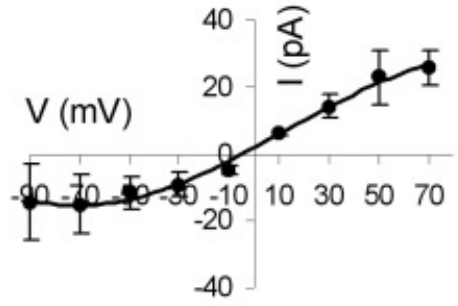

E

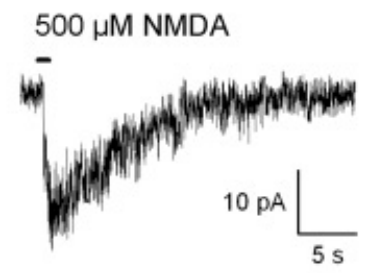

$\mathrm{H}$
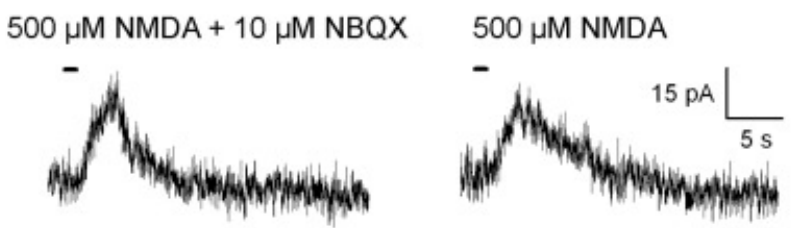

$\mathrm{K}$

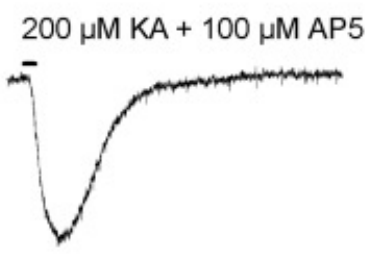

Fig. 9. NMDA receptor expressing amacrine cells. A, currents evoked by the application of NMDA at different holding potentials. $\mathrm{B}$, current-voltage relation (average of 3 cells, reversal potential $-5 \pm 1.2 \mathrm{mV}$ ). The Mg-block at negative holding potentials is not complete, because NMDA was applied in Mg-free solution from the puffer pipette. C, inward current induced by the application of NMDA. D, co-application of NMDA with AP5 effectively blocked the current. E, recovery. F, application of NMDA elicited an outward current at $\mathrm{V}_{\mathrm{H}}=+45 \mathrm{mV}$.. $\mathrm{G}$, this current could not be blocked by the co-application of NMDA and NBQX. H, recovery. I, application of KA induced a prominent inward current. J, co-application of KA and AP5 did not block this current. K, recovery.

Ionotropic receptors of other amacrine cells

There appears to be a difference in our results if the expression of NMDA receptors (Fig. 9) is considered. Out of 15 narrow-field and two glycinergic amacrine cells tested, only seven cells showed NMDA-mediated responses. In contrast, ten out of 13 wide-field and two out of three GABAergic cells were found to express NMDA receptors. This result is in agreement with previous studies on amacrine cell light responses. In the tiger salamander retina, Dixon and Copenhagen (1992) found that transient amacrine cells express NMDA receptors, while sustained amacrine cells do not. In the same species, Maguire (1999) noticed that the two functional cell types have characteristic morphologies: transient amacrine cells possessed wide dendritic fields (diameter $375 \mu \mathrm{m}$ ) while sustained cells had much more narrowly confined dendritic fields (diameter $85 \mu \mathrm{m}$ ). Transient ON-OFF amacrine cells of the turtle retina also seem to possess NMDA receptors (Vigh \& Witkovsky, 2004). Although NMDA receptors do seem to be expressed by certain amacrine cells, the same cells also express AMPA/KA receptors (Thoreson \& Witkovsky, 1999). Non-NMDA agonists are more potent, and while NMDA receptor blockers can only modify light-evoked responses of amacrine cells, non-NMDA 


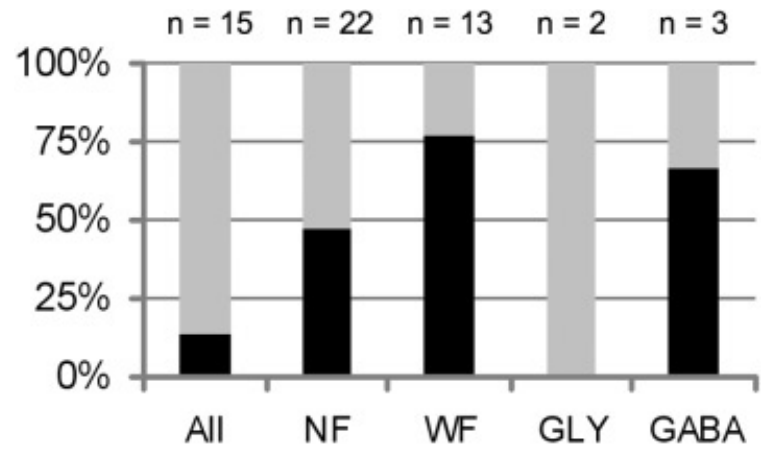

Fig. 10. Summary diagram of the expression of NMDA receptors by the different amacrine cell types (conventions are as in Fig. 7). Black columns: cells express NMDA receptors. Light grey columns: cells express no NMDA receptors. The number of cells investigated is shown on top $(n)$.

receptor antagonists block them completely (Slaughter \& Miller, 1983; Massey \& Miller, 1988; Dixon \& Copenhagen, 1992).

Most amacrine cells expressed AMPA receptors. Thus, $87 \%$ of the narrow-field $(n=45), 85 \%$ of the glycinergic $(n=20), 81 \%$ of the wide-field $(n=21)$, and $78 \%$ of the GABAergic cells $(n=$ 9) showed AMPA receptor-mediated responses. AMPA receptor expression in amacrine cells of different retinae is well established, by both immunocytochemical and physiological studies (reviewed by Thoreson \& Witkovsky, 1999). In fact, most of these studies also reported that AMPA receptors are the dominant GluRs of amacrine cells (tiger salamander: Maguire, 1999; Tran et al., 1999; carp: Shen et al., 1999; rat: Singer \& Diamond, 2003; rabbit: Firth et al., 2003; turtle: Vigh \& Witkovsky, 2004). In our sample, a great variability existed among the individual cell responses to AMPA selective drugs. In each group, we recorded cells where CTZ strongly potentiated the AMPA-evoked current and GYKI strongly inhibited it, other cells in which the two drugs had very little effect, as well as many intermediate cases.

We found that most amacrine cells express KA receptors as well. Thus, $93 \%$ of the narrow-field $(n=43), 95 \%$ of the glycinergic $(n=16), 85 \%$ of the wide-field $(n=26)$, and all of the GABAergic cells $(n=6)$ tested showed KA receptor-mediated responses. Although KA receptor subunits have been found by immunocytochemistry throughout the IPL of the mammalian retina (rat: Brandstätter et al., 1994, 1997; cat: Qin \& Pourcho, 2001; mouse: Haverkamp \& Wässle, 2000; monkey: Grünert al., 2002), to our knowledge this is the first study to report KA receptor activity in amacrine cells. However, comparable to the expression of AMPA receptors we also observed a great variability in the expression of KA receptors.

\section{Acknowledgments}

We thank B. Sinke for excellent technical assistance and I. Odenthal for typing the manuscript. We are grateful to K.K. Ghosh for improving the English text. The study was supported by a grant from the DFG, SFB 269/B4.

\section{References}

BARRY, P.H. (1994). JPCalc, a software package for calculating liquid junction potential corrections in patch-clamp, intracellular, epithelial and bilayer measurements and for correcting junction potential measurements. Journal of Neuroscience Methods 51, 107-116.

Bertolino, M., Baraldi, M., Paenti, C., Braghiroli, D., DiBella, M., VICINI, S. \& CosTA, E. (1993). Modulation of AMPA/kainate receptors by analogoues of diazoxide and cyclothiazide in thin slices of rat hippocampus. Receptors and Channels 1, 267-278.

Bleakman, D., Ballyk, B.A., Schöpp, D.D., Palmer, A.J., Bath, C.P., Sharpe, E.F., Woolley, M.L., Bufton, H.R., KamboJ, R.K., TaRNAWA, I. \& LodGe, D. (1996). Activity of 2,3-benzodiazepines at native rat and recombinant human glutamate receptors in vitro: Stereospecificity and selectivity profiles. Neuropharmacology 35, 1689-1702.

Boos, R., Schneider, H. \& Wässle, H. (1993). Voltage- and transmittergated currents of AII-amacrine cells in a slice preparation of the rat retina. Journal of Neuroscience 13, 2874-2888.

Brandstätter, J.H., Hartveit, E., Sassoè-Pognetto, M. \& Wässle, H. (1994). Expression of NMDA and high-affinity kainate receptor subunit mRNAs in the adult rat retina. European Journal of Neuroscience $\mathbf{6}$, $1100-1112$.

Brandstätter, J.J., Koulen, P. \& Wässle, H. (1997). Selective synaptic distribution of kainate receptor subunits in the two plexiform layers of the rat retina. Journal of Neuroscience 17, 9298-9307.

Brandstätter, J.H., Koulen, P. \& Wässle, H. (1998). Diversity of glutamate receptors in the mammalian retina. Vision Research 38 $1385-1397$.

Chun, M.-H., Han, S.H., Chung, J.W. \& WässLe, H. (1993). Electron microscopic analysis of the rod pathway of the rat retina. Journal of Comparative Neurology 246, 435-458.

DeVries, S.H. (2000). Bipolar cells use kainate and AMPA receptors to filter visual information into separate channels. Neuron 28, 847-856.

Dingledine, R., Borges, K., Bowie, D. \& Traynelis, S.F. (1999). The glutamate receptor ion channels. Pharmacological Reviews 51, 7-61.

Dixon, D.B. \& Copenhagen, D.R. (1992). Two types of glutamate receptors differential excite amacrine cells in the tiger salamander retina. Journal of Physiology 449, 589-606.

Donevan, S.D. \& Rogawski, M.A. (1993). GYKI 52466, a 2,3-benzodiazepine, is a highly selective, noncompetitive antagonist of AMPA/ kainate receptor responses. Neuron 10, 51-59.

Donevan, S.D., Beg, A., Gunther, J.M. \& Twyman, R.E. (1998). The methylglutamate, SYM 2081, is a potent and highly selective agonist at kainate receptors. The Journal of Pharmacology and Experimental Therapeutics 285, 539-545.

Dowling, J.E. \& BoycotT, B.B. (1966). Organization of the primate retina: Electron microscopy. Proceedings of the Royal Society $B$ (London) 166, 80-111.

Firth, S.I., Li, W., Massey, S.C. \& Marshak, D.W. (2003). AMPA receptors mediate acetylcholine release from starburst amacrine cells in the rabbit retina. Journal of Comparative Neurology 466, 80-90.

Fletcher, E.L., Hack, I., Brandstätter, J.H. \& Wässle, H. (2000). Synaptic localization of NMDA receptor subunits in the rat retina. Journal of Comparative Neurology 420, 98-112.

Ghosh, K.K., HaverKamp, S. \& Wëssle, H. (2001). Glutamate receptors in the rod pathway of the mammalian retina. Journal of Neuroscience 21, 8636-8647.

Grünert, U., Haverkamp, S., Fletcher, E. \& Wässle, H. (2002). Synaptic distribution of ionotropic glutamate receptors in the inner plexiform layer of the primate retina. Journal of Comparative Neurology 447, 138-151.

Grünert, U., Lin, B. \& Martin, P.R. (2003). Glutamate receptors at bipolar synapses in the inner plexiform layer of primate retina: Light microscopic analysis. Journal of Comparative Neurology 466, 136-147.

Gu, Z.-Q., Hesson, D.P., Pelletier, J.C. \& Maccecchini, M.-L. (1995). Synthesis, resolution, and biological evaluation of the four stereoisomers of 4-methylglutamic acid: Selective probes of kainate receptors. Journal of Medicinal Chemistry 38, 2518-2520.

Habermann, C.J., Wässle, H. \& Protti, D.A. (2001). AII amacrine cells show a distinct distribution of voltage-dependent calcium channels and ionotropic glutamate receptors. Investigative Ophthalmology and Visual Science 42, E-Abstract 3622.

Hack, I., Frech, M. Dick, O., Peichl, L. \& Brandstätter, J.H. (2001). Heterogeneous distribution of AMPA glutamate receptor subunits at the photoreceptor synapses of rodent retina. European Journal of Neuroscience 13, 15-24.

Hartveit, E. \& Veruki, M.L. (1997). AII amacrine cells express functional NMDA receptors. NeuroReport 8, 1219-1223.

Hartveit, E., Brandstätter, J.H., Sassoè-Pognetto, M., Laurie, D.J., SeEburG, P.H. \& WässLe, H. (1994). Localization and developmental expression of the NMDA receptor subunit NR2A in the mammalian retina. Journal of Comparative Neurology 348, 570-582. 
Haverkamp, S. \& Wässle, H. (2000). Immunocytochemical analysis of the mouse retina. Journal of Comparative Neurology 424, 1-23.

Haverkamp, S., Müller, U., Zeilhofer, H.U., Harvey, R.J. \& Wässle, H. (2004). Diversity of glycine receptors in the mouse retina: Localization of the $\alpha 2$ subunit. Journal of Comparative Neurology 477, 399-411.

Hollmann, M. \& Heinemann, S. (1994). Clones glutamate receptors. Annual Review of Neuroscience 17, 31-108.

Hughes, T.E., Hermans-Borgmeyer, I. \& Heinemann, S. (1992). Differential expression of glutamate receptor genes (GluR1-5) in the rat retina. Visual Neuroscience 8, 49-55.

Kalloniatis, M., Sun, D., Foster, L., Haverkamp, S. \& Wässle, H. (2004). Localization of NMDA receptor subunits and mapping NMDA drive within the mammalian retina. Visual Neuroscience 21, 587-597.

Kew, J.N.C. \& KeMP, J.A. (2005). Ionotropic and metabotropic glutamate receptor structure and pharmacology. Psychopharmacology 179, 4-29.

Kolb, H. \& FAmiglietTi, E.V. (1974). Rod and cone pathways in the inner plexiform layer of cat retina. Science 186, 47-49.

Lee, E.J., Kim, H.J., Lim, E.J., Kim, I.B., Kang, W.S., OH, S.J., Rickman, D.W., Chung, J.W. \& Chun, M.H. (2004). AII amacrine cells in the mammalian retina show disabled-1 immunoreactivity. Journal of Comparative Neurology 470, 372-381.

Li, W., TreXler, E.B. \& Massey, S.C. (2002). Glutamate receptors at rod bipolar ribbon synapses in the rabbit retina. Journal of Comparative Neurology 448, 230-248.

LINN, D.M. \& MASSEY, S.C. (1991). Acetylcholine release from the rabbit retina mediated by NMDA receptors. Journal of Neuroscience 11, $123-133$.

Linn, D.M., Blazynski, C., Redburn, D.A. \& Massey, S.C. (1991). Acetylcholine release from the rabbit retina mediated by kainate receptors. Journal of Neuroscience 11, 111-122.

Lodge, D., Jones, M.G. \& Palmer, A.J. (1991). Excitatory amino acids: New tools for old stories or pharmacological subtypes of glutamate receptors: Electrophysiological studies. Canadian Journal of Physiology and Pharmacology 69, 1123-1128.

MacNeil, M.A. \& Masland, R.H. (1998). Extreme diversity among amacrine cells: Implications for function. Neuron 20, 971-982.

MaguiRe, G. (1999). Rapid desensitization converts prolonged glutamate release into a transient EPSC at ribbon synapses between retinal bipolar and amacrine cells. European Journal of Neuroscience 11, 353-362.

MARC, R.E. (1999a). Mapping glutamatergic drive in the vertebrate retina with a channel-permeant organic cation. Journal of Comparative Neurology 407, 47-64.

MARC, R.E. (1999b). Kainate activation of horizontal, bipolar, amacrine, and ganglion cells in the rabbit retina. Journal of Comparative Neurology $407,65-76$.

MasLand, R.H. (2001). The fundamental plan of the retina. Nature Neuroscience 4, 877-886.

Massey, S.C. \& Miller, R.F. (1988). Glutamate receptors of ganglion cells in the rabbit retina: Evidence for glutamate as a bipolar cell transmitter. Journal of Physiology 405, 635-655.

Menger, N. \& Wässle, H. (2000). Morphological and physiological properties of the A17 amacrine cells of the rat retina. Visual Neuroscience 17, 769-780.

Menger, N., Pow, D.V. \& Wässle, H. (1998). Glycinergic amacrine cells of the rat retina. Journal of Comparative Neurology 401, 34-46.

Mørkve, S.H., Veruki, M.L. \& Hartveit, E. (2002). Functional characteristics of non-NMDA-type ionotropic glutamate receptor channels in AII amacrine cells in rat retina. Journal of Physiology 542, 147165.

Müller, F., Greferath, U., Wässle, H., Wisden, W. \& Seeburg, P. (1992). Glutamate receptor expression in the rat retina. Neuroscience Letters 138, 179-182.

O’Brien, B.J., AnNies, M. \& WÄssle, H. (2002). Ionotropic glutamate receptors of amacrine and ganglion cells in mouse retina. Investigative Ophthalmology and Visual Science 43, E-Abstract 4768.

Ozawa, S., KamiYa, H., Tsuzuki, K. (1998). Glutamate receptors in the mammalian central nervous system. Progress in Neurobiology 54, 581-618.

Palmer, A.J. \& Lodge, D. (1993). Cyclothiazide reverses AMPA receptor antagonism of the 2,3-benzodiazepine, GYKI 53655. European Journal of Pharmacology 244, 193-194.

Peng, Y.-W., Blackstone, C.D., Huganir, R.L. \& Yau, K.-W. (1995). Distribution of glutamate receptor subtypes in the vertebrate retina. Neuroscience 66, 483-497.

Pourcho, R.G. \& Goebel, D.J. (1985). A combined Golgi and autoradio- graphic study of $\left({ }^{3} \mathrm{H}\right)$-glycine-accumulating amacrine cells in the cat retina. Journal of Comparative Neurology 233, 473-480.

QIN, P. \& Pourcho, G. (1996). Distribution of AMPA-selective glutamate receptor subunits in cat retina. Brain Research 710, 303-307.

QIN, P. \& Pourcho, G. (1999a). Localization of AMPA-selective glutamate receptor subunits in the cat retina: A light- and electronmicroscopic study. Visual Neuroscience 16, 169-177.

QIN, P. \& Pourcho, G. (1999b). AMPA-selective glutamate receptor subunits GluR2 and GluR4 in the cat retina: An immunocytochemical study. Visual Neuroscience 16, 1105-1114.

Qin, P. \& Pourcho, G. (2001). Immunocytochemical localization of kainate-selective glutamate receptor subunits GluR5, GluR6, and GluR7 in the cat retina. Brain Research 890, 211-221.

Sheardown, M.J., Nielsen, E.O., Hansen, A.J., Jacobsen, P. \& Honore, T. (1990). 2,3-dihydroxy-6-nitro-7-sulfamoyl-benzo(F)quinoxaline: A neuroprotectant for cerebral ischemia. Science 247, 571-574.

Shen, Y., Zhou, Y. \& YANG, X.-L. (1999). Characterization of AMPA receptors on isolated amacrine-like cells in carp retina. European Journal of Neuroscience 11, 4233-4240.

Shen, W., Finnegan, S.G. \& Slaughter, M.M. (2004). Glutamate receptor subtypes in human retinal horizontal cells. Visual Neuroscience 21, 89-95.

Singer, J.H. \& Diamond, J.S. (2003). Sustained $\mathrm{Ca}^{2+}$ entry elicits transient postsynaptic currents at a retinal ribbon synapse. Journal of Neuroscience 23, 10923-10933.

Slaughter, M.M. \& Miller, R.F. (1983). The role of excitatory amino acid transmitters in the mudpuppy retina: An analysis with kainic acid and N-methyl aspartate. Journal of Neuroscience 3, 1701-1711.

Thoreson, W.B. \& Witkovsky, P. (1999). Glutamate receptors and circuits in the vertebrate retina. Progress in Retinal and Eye Research 18, $765-810$.

Tran, M.N., Higgs, M.H. \& Lukasiewicz, P.D. (1999). AMPA receptor kinetics limit retinal amacrine cell excitatory synaptic responses. Visual Neuroscience 16, 835-842.

Trexler, E.B., Li, W. \& Massey, S.C. (2003). Expression of NMDAsensitive glutamate receptors on AII amacrine cells. Investigative Ophthalmology and Visual Science 44, E-Abstract 2070.

VANEY, D.I. (1991). The mosaic of amacrine cells in mammalian retina Progress in Retinal Research 9, 49-100.

Veruki, M.L., Mørkve, S.H. \& Hartveit, E. (2003). Functional properties of spontaneous EPSCs and non-NMDA receptors in rod amacrine (AII) cells in the rat retina. Journal of Physiology 549, 759-774.

VIGH, J. \& WitKovskY, P. (2004). Neurotransmitter actions on transient amacrine and ganglion cells of the turtle retina. Visual Neuroscience 21, 1-11.

Vyklicky, L. JR., Patneau, D.K. \& Mayer, M.L. (1991). Modulation of excitatory synaptic transmission by drugs that reduce desensitization at AMPA/kainate receptors. Neuron 7, 971-984.

Wëssle, H. (2004). Parallel processing in the mammalian retina. Nature Reviews Neuroscience 5, 747-757.

WiLDING, T.J. \& HuETTNER, J.E. (1995). Differential antagonism of alphaamino-3-hydroxy-5-methyl-4-isoxazolepropionic acid-preferring and kainate-preferring receptors by 2,3-benzodiazepines. Molecular Pharmacology 47, 582-587.

Zafra, F., Aragon, C., Olivares, L., Danbolt, N.C., Giménez, C. \& Storm-Mathisen, J. (1995). Glycine transporters are differentially expressed among CNS cells. Journal of Neuroscience 15, 3952-3969.

Zeilhofer, H.U., Studler, B., Arabadzisz, D., Schweizer, C, Ahmadi, S., LAYH, B., BösL, M.R. \& Fritschy, J.-M. (2005). Glycinergic neurons expressing enhanced green fluorescent protein in bacterial artificial chromosome transgenic mice. Journal of Comparative Neurology 482, 123-141.

Zhang, C., Hamassaki-Britto, D.E., Britto, L.R.G. \& Duvoisin, R.M (1996). Expression of glutamate receptor subunit genes during development of the muse retina. NeuroReport 8, 335-340.

Zhou, Z.J. \& FAIN, G.L. (1995). Neurotransmitter receptors of starburst amacrine cells in rabbit retinal slices. Journal of Neuroscience $\mathbf{1 5}$, $5334-5345$.

Zhou, L.-M., Gu, Z.-Q., Costa, A.M., Yamada, K.A., Mansson, P.E., Giordano, T., Skolnick, P. \& Jones, K.A. (1997). (2S,4R)-4Methylglutamic acid (SYM 2081): A selective, high-affinity ligand for kainate receptors. Journal of Pharmacology and Experimental Therapeutics 280, 422-427.

Zhou, C. \& DACHEUX, R.F. (2004). AII amacrine cells in the rabbit retina possess AMPA-, NMDA-, GABA-, and glycine-activated currents. Visual Neuroscience 21, 181-188. 